\title{
PROPOSTA METODOLÓGICA PARA INQUÉRITO DOMICILIAR COM POPULAÇÕES IDOSAS EM UM CENTRO URBANO DO ESTADO DO RIO DE JANEIRO (BRASIL) *
}

\author{
Renato P. Veras" \\ Sidney Dutra da Silva". \\ Cristina A.M. Souza" \\ Rosane Milioli" \\ Fátima Ventura*
}

\begin{abstract}
VERAS, R.P. et al. Proposta metodológica para inqućrito domiciliar com populaçð̋es idosas em um centro urbano do Fstado do Rio de Janciro (Brasil). Rev. Saúde públ., S. Paulo, 23: 429-38, 1989.

RESUMO: São apresentados a metodologia utilizada no projeto de pesquisa de idosos no Rio de Janeiro, desenvolvido no Instituto de Medicina Social da Universidade do Estado do Rio de Janeiroe os estágios relativos à preparaçăo do trabalho de campo $\mathrm{em}$ um inquérito domiciliar. Săo discutidos os indicadores utilizados no processo de identificação de distritos homogeneos, a definiçăo do universo amostral e os procedimentos empregados na atividade de enumeração.
\end{abstract}

DESCRITORES: Inquéritos epidemiológicos. Métodos. Idoso.

\section{INTRODUÇĀO}

Com o crescimento da população idosa no Brasil $1,2,11,13,15^{* * * *}$ vários grupos de pesquisas estão iniciando estudos epidemiológicos com $o$ intuito de identificar o idoso brasilciro *** O presente artigo tem por objetivo participar do debate sobre a produção de conhecimento na árca da terccira idade, apresentando uma proposta de metodologia que possibilite a avaliação da saúde física e mental, das condiçōes econômicas e sociais e da autonomia do dia-a-dia deste grupo populacional

O projeto ora em desenvolvimento pelo programa de Epidemiologia da Terccira Idade do
Instituto de Medicina Social da Universidade do Estado do Rio de Janeiro (IMS/UERJ) pretende aplicar um inquérito domiciliar junto à população idosa do Município do Rio de Janeiro. Para isto, foram desenvolvidos um questionário multidimensional, um manual de instrução e um livro de códigos $^{14}$.

A opção por um instrumento que cubra vários aspectos da vida do idoso deveu-se ao interesse em que os resultados obtidos sejam utilizados na formulação de políticas e tomada de decisões.

Scrão discutidos os indicadores sócio-econômicos demográficos utilizados no estudo, a definição do universo amostral, o processo e as difi-

Subvencionado pela Financiadora de Estudos c Projetos (FINRI) Processo n² 42.86.0911.00 e pela Fundaçåo de Amparo à Pesquisa do Estado do Rio de Janeiro (FAPERJ). Processo n 170.266-88.

Instituto de Medicina Social da Universidade do Estado do Rio de Janeiro - Rua São Francisco Xavier, 525 - 20550 - Rio de Janeiro, RJ - Brasil.

* * Pesquisadoras participantes do projeto de pesquisa "Avaliaçăo Multidimensional de Populaçăo Idosa no Município do Rio de Janeiro".

*** Inclua-se: Berquó, E.S. e leite, V. de M. Algumas considerações sobre a demografia da populaçăo idosa no Brasil, 1987. (Dados inéditos).

**** No Brasil, nos dias atuais, os principais grupos de pesquisa såo os coordenados por: Prof. Luiz R. Ramos (Escola Paulista de Medicina, SP), Dr. Renato Maja (Coordenador do Programa da Terceira Idade do Ministério da Saúde, DF), Dr. Carlos Dora (Secretaria de Saúde do Fstado do Rio Grande do Sul, RG), Prof. Mário Sayeg (Escola Nacional de Saúde Pública, RJ), Dr. Ricardo Frederico Neuperi (IPI:A, DF), Prof. Antônio Jordåo Neto (Universidade de Såo Paulo, SP), Prof. Eurico Thomas Carvalho Filho (Hospital das Clínicas Universidade de Săo Paulo, SP)e Dr. Ulysses Gabriel de Vasconcelos Cunha (IPSEMG, MG).

***** Como populaçăo idosa ou terceira idade, consideram-sc individuos de sessenta anos ou mais. 
culdades enfrentadas no trabalho de enumeraçāo em um grande centro urbano.

\section{CARACTERIZAÇÃo DAS ÁREAS AMOSTRAIS}

A escolha de um estudo que propiciasse elementos para a implementação de serviços assistenciais levou a que se considerasse um aspecto de especial relevância em estudos populacionais. $\mathbf{O}$ Rio de Janeiro, como todo o Brasil, apresenta grandes disparidades econômicas e sociais, e este fato deve ser considerado num desenho de projeto que queira fornecer subsídios para o planejamento das ações médico-sociais. Num quadro de profundas desigualdades regionais, o país engloba bolsōes de miséria absoluta e regiōes mais desenvolvidas e industrializadas. Como expressão destas iniqüidades, o indicador expectativa de vida ao nascer para o Brasil mostra uma posição que não representa as regiōes mais ricas, como Rio de Janeiro e São Paulo, e também pouca relaçāo possui com os estados mais pobres, que têm uma expectativa de vida ao nascer muito aquém daquelas, devido à baixa qualidade de vida de suas populações ${ }^{1,4,11}$.

A exemplo do que ocorre em todo o Brasil, o Município do Rio de Janeiro também apresenta disparidades sócio-econômicas entre suas populações, apesar de se situar com um bom padrâo em relação a outros Estados e regiōes do país. No Rio de Janeiro existem áreas de extrema carência que abrigam grande número de famílias de baixa renda e que convivem com insuficiência de serviços essenciais, como saneamento básico, transporte e assistência médica, entre outros. Em contraposição, há bairros onde esta situação praticamente inexiste, ou se expressa de forma menos intensa. Assim, na mesma cidade, condiçōes precárias e de insuficiência são encontradas lado a lado com condiçōes modernas e fartas, semelhantes às de algumas áreas ricas de países desenvolvidos.

Levando estes fatos em consideração, entendemos ser correta a preocupação de $\operatorname{Ramos}^{9}$, no desenho da metodologia do estudo realizado em São Paulo, quando contemplou estratos sócioeconômicos distintos daquela cidade.

Com base neste quadro, a discussão sobre os critérios de escolha dos indicadores mais eficazes para o recorte de uma amostra em pesquisas populacionais ganha especial relevância, pois é a partir da definição deste critério que a realidade social será apreendida de maneira representativa.

\section{Os indicadores}

Devido às discrepâncias sociais e econômicas da cidade do Rio de Janeiro, entendemos que em vez de se olhar a cidade como um todo homogêneo e obter um resultado que não reflita as condiçōes de vida da camada mais pobre - como também da mais rica - , julgou-se mais adequado observar separadamente algumas regiōes da cidade, a fim de possibilitar um estudo mais criterioso e adequado que reflita as realidades específicas. Deste modo, a cidade foi avaliada pelas "áreas homogêneas", isto E, bairros e segmentos sociais com padrões similares de facilidades. Para isto, utilizou-se da divisão do município em distritos, elaborada pela Fundação Instituto Brasileiro de Geografia e Estatística (IBGE), a partir de critérios de classificação por características semelhantes, o que confere a essas áreas um relativo grau de representatividade enquanto realidades do Rio de Janeiro. No último censo demográfico, o Município do Rio de Janeiro (município número 455) foi dividido em 24 distritos, que na época correspondiam às 24 regiōes administrativas . $O$ intuito é de definir, a partir de um conjunto de indicadores, três distritos que melhor representem a população de um distrito rico, médio e pobre da cidade do Rio de Janeiro. As categorias de população rica, média e pobre estão sendo empregadas num sentido muito amplo, para cobrir uma variedade de conceitos. Estas categorias serão utilizadas para distinguir um grupo de pessoas em relação à sua condição econômica, prestígio, status e modo de vida. Em outras palavras, procurou-se obter uma amostra que, respeitando os limites geopolíticos, fosse representativa da populaçāo do Município do Rio de Janeiro no que diz respeito à sua heterogeneidade. Portanto, uma amostra que representasse não a população do município como um todo, mas o espectro de variaçōes no tocante aos indicadores utilizados. Para tal caracterização, a escolha recaiu nos seguintes indicadores:

renda média domiciliar; infra-estrutura sanitária (água e esgoto);

* No censo de 1980 eram identicas as áreas que compreendiam os 24 distritos definidos pelo IBGE, e as 24 Regióes Administrativas (RA) estabelecidas pelo Município do Rio de Janeiro. Atualmente, a cidade do Rio de Janeiro possui 30 RAs. Possivelmente, no censo do próximo ano, o IBGE irá trabalhar com 30 distritos. 
número de filhos entre mulheres de 15 a 49 anos;

proporção de pessoas idosas;

número de estabelecimentos bancários.

Tendo em vista o interesse de trabalhar apenas com os dados oficiais, as informaçōes foram obtidas no IBGE e no Banco Central do Brasil" Excetuando a informação sobre os bancos, todas as demais foram processadas e tabuladas pela Gcrencia de Sistema de Disseminaçāo e Informática do IBGE/CDDI (Centro de Documentação e Disseminaçāo de Informaçōes).

Os dois primeiros indicadores - renda e água/esgoto - são tradicionalmente usados na caracterização de estratos sociais ${ }^{35,8,10,12}$.

$\mathrm{O}$ indicador número de filhos, além de bastante sensível na detecçāo de segmentos sócioeconômicos," possui a qualidade de ser uma informação obtida do censo demográfico, diminuindo, deste modo, o problema do sub-registro que se verifica nas informações obtidas através do Registro Civil (a exemplo do indicador mortalidade infantil).

Com o intuito de avaliar as condiçōes de vida e saúde da população idosa de São Paulo, Ramos ${ }^{9}$ realizou uma análise das condiçōes dos idosos por distrito e obteve dados sugestivos de que a proporção de idosos em uma determinada população corrclaciona-se fortemente com outros indicadores sociais, tais como renda média familiar e disponibilidade sanitária. Desta forma, a concentração de idosos em um distrito pode ser utilizada como um indicador geral das condições de vida de uma população.

$O$ indicador número de estabelccimentos bancários foi considerado porque é sabido que as agências bancárias se localizam em áreas onde existem uma concentração de riqueza representada principalmente por comércio, indústrias e/ou bairros onde se concentra população de alto poder aquisitivo. Este indicador foi utilizado por
Gentile de $\mathrm{Mcllo}^{7}$ quando da discussão a respeito da formação do profissional de medicina e das pressōes originárias do mercado de trabalho médico.

Ao se optar por este conjunto de cinco indicadores, sabia-se que, em alguns distritos, certos indicadores (por exemplo, número de agências bancárias e saneamento) iriam produzir resultados que não reflctiriam corretamente as condições sócio-econômicas predominantes da população ncla residente. Na região central da cidade do Rio de Janeiro existe uma importante concentração de estabclccimentos ligados ao setor financeiro, sem que isto, no entanto, signifique que esta seja uma área de moradia da população rica; aliás, neste distrito, a população residente é em geral constituída de pessoas de baixo poder aquisitivo, por se tratar de uma área de concentração comercial e de prestação de serviços, sem as facilidades e características dos bairros residenciais. Do mesmo modo, alguns distritos, principalmente os localizados nas regiñes mais antigas da cidade (por ex., Santo Cristo, Gamboa, Saúde, entre outros), possuem há muito redes de água e esgoto. No entanto, abrigam, predominantemente, uma populaçāo de baixo poder aquisitivo. Situação inversa ocorre em alguns dos distritos de ocupação mais recente, como a Barra da Tijuca, que, apesar de concentrar a maior renda média familiar do município, ainda possui uma precária estrutura sanitária.

Para compensar possiveis falhas dos menos precisos, a opção foi trabalhar com um conjunto de indicadores, pois deste modo imprecisões localizadas seriam corrigidas e ajustadas pelos demais.

O procedimento utilizado foi o mesmo para cada um dos 24 distritos do Município do Rio de Janeiro. Os indicadores foram aplicados, e cada um dos distritos recebeu um escore variando de 1 , para o "melhor", e 24 para o "pior" colocado. Todos os distritos, em relação ao indicador observado, receberam um escore e foram colocados

* O IBGE indaga sobre mulheres de 15 anos ou mais, número de fillhos nascidos vivos, número de filhos nascidos mortos, número de filhos vivos na data do censo, descrevendo o sexo e a data de nascimento (més e ano) do último filtho nascido vivo. Definimos, para o projeto, processsr as informaçđes das mulheres de até 49 anos.

* * As informaçð̃es do Banco Central do Brasil foram recolhidas na relação de agências e dependências bancárias existentes por municípios - Planilha VICF 60982.

No IBGE, as informaçðes foram obtidas do Recenseamento Geral de 1980.

*** A associação entre níveis de número de filhos e "processo de modernizaçăo da sociedade" é bastante questionada (Ver, a respeito, discussåo do "Simpósio de Pesquisa Demográfica no Brasil" e em particular artigo de Carvalho". Aceitamos a tese - principalmente quando se utiliza um indicador - de que fecundidade é influenciada por um conjunto de fatores extrínsecos à categoria "estrato social". No entanto, em um recorte exploratório e inicial, em um grande centro urbano como a cidade do Rio de Janeiro, este indicador revelou consistente associaçăo negativa entre "riqueza" e núme ro de filhos. 
numa escala. Este procedimento foi realizado para os cinco indicadores. Ao final, foi produzida uma tabela contendo as pontuaçōes de todos os distritos para todos os indicadores, onde $e$ apresentado o total de pontos que cada distrito obteve (Tabela). Deste modo, produziu-se uma listagem dos distritos do Município do Rio de Janeiro em ordem decrescente, podendo-se, a partir das posições obtidas, selecionar os três distritos onde o inquérito domiciliar será realizado.
Portanto estes indicadores foram analisados de modo semelhante, recebendo um mesmo peso, e considerados no mesmo grau de importância. Entendeu-se que seria mais adequado tratá-los de modo igual, em vez de dar grau diferenciado a este ou aquele indicador. A valoração de um determinado indicador em relação a outro implicaria considerar que algum deles fosse o melhor; $\mathrm{e}$, se isto fosse verdadeiro, seria arbitrário dizer quantas vezes esse indicador seria melhor em relação a um

TABELA

Pontuação por regĩo administrativa dos Indicadores demográficos e sócio-econômicos

\begin{tabular}{|c|c|c|c|c|c|c|c|c|}
\hline \multicolumn{2}{|c|}{ Região Administrativa } & \multirow{2}{*}{$\frac{\begin{array}{c}\text { Agência } \\
\text { bancária }\end{array}}{21}$} & \multirow{2}{*}{$\frac{\begin{array}{c}\text { Proporção de } \\
\text { idosos }\end{array}}{11}$} & \multirow{2}{*}{$\begin{array}{c}\begin{array}{c}\text { Número de } \\
\text { filhos }\end{array} \\
18\end{array}$} & \multirow{2}{*}{$\begin{array}{c}\begin{array}{c}\text { Água e } \\
\text { esgoto }\end{array} \\
14\end{array}$} & \multirow{2}{*}{$\begin{array}{c}\begin{array}{c}\text { Renda } \\
\text { familiar }\end{array} \\
20\end{array}$} & \multirow{2}{*}{$\begin{array}{c}\begin{array}{c}\text { Total de } \\
\text { pontos }\end{array} \\
84\end{array}$} & \multirow{2}{*}{$\begin{array}{c}\begin{array}{c}\text { Ordem } \\
\text { final das } \\
\text { RAs }\end{array} \\
20\end{array}$} \\
\hline I & - Portuária & & & & & & & \\
\hline II & - Centro & 01 & 04 & 03 & 02 & 13 & 23 & 03 \\
\hline III & - Rio Comprido & 20 & 08 & 10 & 20 & 10 & 68 & 13 \\
\hline IV & - Botafogo & 03 & 05 & 02 & 03 & 04 & 17 & 02 \\
\hline $\mathrm{v}$ & - Copacabana & 02 & 01 & 01 & 01 & 03 & 08 & 01 \\
\hline $\mathrm{VI}$ & - Lagoa & 04 & 10 & 08 & 18 & 02 & 42 & 06 \\
\hline VII & - São Cristóvão & 11 & 12 & 12 & 19 & 18 & 72 & 15 \\
\hline VIII & - Tijuca & 05 & 03 & 04 & 10 & 05 & 27 & 04 \\
\hline IX & - Vila Isabel & 13 & 06 & 05 & 04 & 06 & 34 & 05 \\
\hline $\mathrm{x}$ & $-\cdot R$ amos & 06 & 15 & 16 & 21 & 17 & 75 & 16 \\
\hline $\mathrm{XI}$ & - Penha & 10 & 17 & 17 & 13 & 19 & 76 & 17 \\
\hline xil & - Méier & 08 & 14 & 13 & 12 & 14 & 61 & 12 \\
\hline XIII & - Engenho Novo & 16 & 07 & 09 & 05 & 08 & 45 & 07 \\
\hline $\mathrm{XIV}$ & - Irajá & 16 & 16 & 15 & 07 & 15 & 69 & 14 \\
\hline $\mathrm{XI}$ & - Madureira & 07 & 13 & 11 & 08 & 16 & 55 & 09 \\
\hline $\mathrm{XVI}$ & - Jacarepaguá & 11 & 18 & 20 & 17 & 11 & 77 & 18 \\
\hline $\mathrm{XV}$ & - Bangu & 14 & 21 & 22 & 15 & 22 & 94 & 21 \\
\hline XVIII & - Campo Grande & 16 & 22 & 23 & 22 & 23 & 106 & 23 \\
\hline XIX & - Santa Cruz & 19 & 23 & 24 & 23 & 24 & 113 & 24 \\
\hline $\mathrm{XX}$ & - Ilha do Govemador & 09 & 19 & 14 & 11 & 07 & 60 & 11 \\
\hline $\mathrm{XXI}$ & - Ilha de Paquetá & 23 & 02 & 07 & 06 & 12 & 50 & 08 \\
\hline XXII & - Anchieta & 22 & 20 & 21 & 16 & 21 & 100 & 22 \\
\hline XXIII & - Santa Tereza & 24 & 09 & 06 & 09 & 09 & 57 & 10 \\
\hline XXIV & - Barra da Tijuca & 15 & 24 & 19 & 24 & 01 & 83 & 19 \\
\hline
\end{tabular}


outro. Logo, estabelecer peso diferenciado para os indicadores seria uma medida casuística e sem sustentação teórica, que se optou por não usar.

Também foi opção do desenho do estudo tratar os escores dos indicadores como uma variável discreta, sem discriminar as variaçöes existentes entre os intervalos das escalas. A fim de observar se estes intervalos produziriam distorções nos resultados finais, e também verificar se o conjunto de indicadores definidos corrigiria as variações apontadas, conforme preocupação já menciona$\mathrm{da}$, procedeu-se ao teste estatístico que utiliza a técnica de componentes principais.

Este teste consiste em determinar entre vários indicadores os que melhor explicam o comportamento dos dados, além de determinar novos indicadores - formados a partir da combinação dos anteriores. Esta técnica permite trabalhar com unidades de medidas diferentes. No presente estudo trabalhou-se com proporção (número de filhos, saneamento e proporçāo de idosos) e somatório (renda familiar e número de agências bancárias). A técnica de componentes principais forne- ce a melhor combinação entre os indicadores utilizados.

$\mathrm{Na}$ análise da Figura, o eixo das abscissas é formado pela fusão dos cinco indicadores (denominado estratos sociais), e o eixo das ordenadas representa o contraste entre os indicadores saneamento e renda. Percebe-se que os distritos Barra da Tijuca e Lagoa, apesar de serem os de maior renda familiar no município, possuem condições de saneamento precárias. Utilizando-se estes indicadores, foi possível atenuar a força de um indicador menos preciso e estabelecer a compensação, conforme é demonstrado no gráfico. No eixo das abscissas observa-se, da direita para a esquerda, a confirmação dos três distritos selecionados para o estudo.

A seleção das áreas indicou o distrito 10 (Copacabana) em primeiro lugar; o distrito 17 (Méier), que se posicionou na situaçāo intermediária, e o distrito 24 (Santa Cruz), que apresentou os "piores" resultados, colocando-se em último lugar.

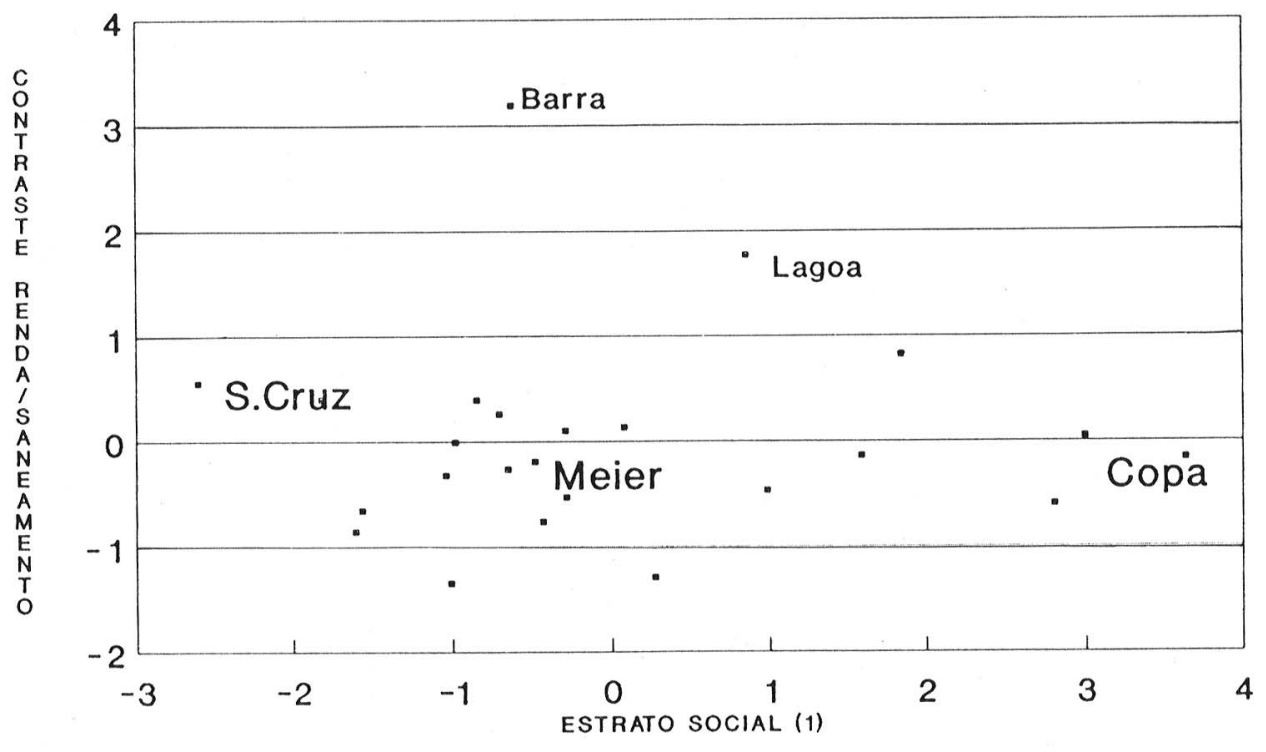

Nota (1) $\mathrm{O}$ indicador estrato social foi composto a partir da combinação dos 5 indicadores utilizados nesse estudo.

Fıgura - Representaçăo gráfica dos indicadores sócio-econômicos demográficos: Técnica de componentes principais. 


\section{PROCESSO AMOSTRAL}

Definidas as três áreas (distritos), solicitouse ao IBGE os mapas das ruas desses distritos, agrupadas em setores censitários * $\mathrm{O}$ distrito 10 possui 389 setores, o 17, 379 e o 24, 160. O passo seguinte foi solicitar a listagem dos setores definidos pelo IBGE como especiais para serem excluídos do processo de amostra.

$A$ inexistência de listas de endereços atualizados, ou de quaisquer outras listagens que possibilitem a localizaçāo de parcelas da populaçāo, dificulta a seleção prévia de qualquer amostra domiciliar, exigindo-se para isto um trabalho exaustivo de enumeração. Este trabalho consiste em um levantamento completo feito pelos pesquisadores, que, tomando como base cada setor censitário, seguem o percurso nele assinalado, identificando todos os moradores com 60 anos ou mais, registrando além do nome, sexo, idade, endereço completo para contatos que deverão ser travados em função da entrevista, caso esta pessoa venha a ser, aleatoriamente selecionada.

Para definição do tamanho da amostra, foram arbitrados um intervalo de confiança de $95 \%$, com nívcl de significância de 0.05 , e uma prevalência para os "casos" em saúde mental detectados pclo questionário em $20 \%$. Aplicando-se a fórmula " de dimensionamento da amostra por aleatória simples ${ }^{3}$, o produto informa o tamanho da amostra para cada distrito.

$$
\mathbf{n}=\frac{N p q Z_{o}^{2}}{N d^{2}+Z_{o}^{2}+p q}
$$

Contando com a probabilidade de 5 a $8 \%$ de perdas e recusas, optou-se por padronizar a amostra em 260 idosos para cada um dos três distritos.
A fim de se obter a amostra de 260 idosos por distrito, algumas possibilidades de seleção podem ser utilizadas.

- A primeira opção seria enumerar todos os setores censitários e após identificar a população idosa, selecionar $1 \%$ dos idosos de cada um desses setores. Este trabalho seria extremamente exaustivo e demandaria uma grande soma de recursos e tempo.

- A possibilidade inversa seria a de selecionar $1 \%$ dos setores censitários e entrevistar todos os idosos desses setores. $O$ problema deste procedimento seria o pequeno número de setores e a possibilidade de a seleção incluir algum setor pouco representativo do distrito.

- Deste modo, a solução encontrada foi algo intermediário. Selecionou-se $5 \%$ dos setores censitários e procedeu-se à seleção de $20 \%$ dos idosos residentes nesses setores. Para se obter este percentual de idosos no interior do setor, o procedimento utilizado foi o da segmentação do setor. Este consiste em fracionar o setor em cinco segmentos, selecionar um dos segmentos e proceder à enumeração de todos os idosos pertencentes a esse segmento

Este procedimento leva vantagem em relação aos outros dois sugeridos, pois evita-se o alto custo e o tempo gasto do primeiro e trabalha-se com uma amostra mais confiável do que a da segunda opção.

Tendo em vista que a população idosa de Copacabana em 1980 era de 38.134 e a projeção para 1988 é de 45.775, para nossa cota de 260 idosos, e contando com alguma reserva, precisouse de menos de $1 \%$ desta população. Portanto, dos 389 setores de Copacabana selecionaram-se 5\% de setores(19) e enumerou-se $20 \%$ de idosos resi-

Os municípios foram dividos em distritos e os distritos em setores. O setor - unidade básica de coleeta - constitui-se de área territorial contínua localizada em uma só situaç̧oo (cidade, vila, área urbana isolada, aglomerado rural ou zona ru ral) do mesmo distrito administrativo. O número de setores em cada distrito varia de conformidade com a área, as dificuldades de transporte, a densidade da populaçáo e dos donicilios.

* * Os setores especiais correspondem: a domicilios coletivos com capacidade para alojamento para mais de 50 pessoas (hotel, asilos, acampamento, quartel etc.), aglomerados especiais urbanos (favelas, mocambos, alagadas) e aldeias indígenas.

Tratando-se de um questionário multidimensional, optou-se pela prevaléncia do segmento de saúde mental devido aos seguintes principais motivos: existem estudos recentes a respeito desta prevaléncia obtida at ravés de instrumento semelhante, e é no segmento de saúde mental que se irá processar o estudo de confiabilidade e validaçáo do questionário BOAS. $n=$ tamanho da amostra; $N=$ total da populaçáo idosa no dist rito; $p=$ prevaléncia; $q=1-p ; Z_{0}=$ coeficiente de confiança; $\mathrm{d}=$ nivel de significancia.

**** Para o dimensionamento do tamanho das amostras utilizou-se a populaçáo idosa estimada de 1988, que apresentava os seguintes valores: Copacabana $N=45.775 ;$ Mćier $N=42.547$; Santa Cruz $N=11.249$.

***** Este procedimento foi realizado para os distritos de Copacabana e Méier. Já para Santa Cruz, que necessitava de uma amostra de 3\%, utilizou-se método semelhante, apenas ampltando o percentual de setores e de idosos selecionados. 
dentes nesses setores. Para o Méier, que em 1980 tinha uma população idosa de 36.645 , e uma projeção para 1988 de 42.547 , utilizou-se procedimento semelhante ao de Copacabana. Já em Santa Cruz, para se atingir a amostra de 260 idosos, precisou-se de pouco menos de $3 \%$ deste distrito, tendo em vista que a projeção de sua população de idosos para 1988 é de 11.249 (populaçāo em 1980, 8.005). Para este distrito sorteou-se $10 \%$ dos setores censitários e em cada setor foram enumerados $30 \%$ da populaçāo idosa, obtendo-se deste modo a cota de 3\% de idosos de Santa Cruz.

Embora se tenha usado para o dimensionamento da amostra um modelo de amostragem aleatória simples, trabalhou-se na realidade com um esquema de amostragem por conglomerados em dois estágios, sendo o primeiro estágio o setor censitário e o segundo, o domicilio.

Tal procedimento implica que o erro de amostragem para a estimativa a ser feita será um pouco superior ao da amostra em virtude do efeito de conglomeraçāo existente no setor censitário. Para se obter o mesmo erro estabelecido quando do dimensionamento da amostra, ter-se-ia que aumentar a amostra de conglomerados. Não se dimensionou a amostra considerando conglomerados, tendo em vista o desconhecimento das medidas de homogeneidade no setor para as variáveis objeto de estudo.

\section{O TRABALHO DE CAMPO NA ENUMERAÇÃO}

Se a desigualdade existente entre a qualidade de vida da população do município levou à adoção de critérios que permitissem estratificá-lo para a amostra, da mesma forma o trabalho de campo precisa se orientar em funçāo das diferentes realidades confrontadas, pois é no campo que o projeto encontra seu oljeto, cria com ele uma relaçāo e sobre ele produz um conhecimento. Neste sentido, os procedimentos desenvolvidos precisam ser constantemente adequados, seja na elaboração de novas estratégias de abordagem seja na construção de instrumentos que viabilizem o processo de coleta de informações.

A especificidade de cada universo social que se penetra requer procedimentos diferenciados que só se tornam efetivos através do olhar treinado do observador, que vai capturando o que pode ser significativo e apreendendo os códigos que perpassam as relaçōes. É esse mesmo olhar que, enquanto revela maneiras de relacionar-se, atualiza e testa os dados secundários que informam sobre aquela realidade. Na dinâmica do trabalho de campo, o papel do pesquisador/entrevistador é fundamental na apreensão do real, a despeito do papel que desempenha o questionário em um survey. Pesquisador e questionário são ambos instrumentos que se completam na atividade de campo. Aquilo que o questionário, por razōes metodológicas que lhe impõem um recorte, deixa de fora da moldura, o olhar do pesquisador encontra campo aberto para focalizar. Este exercício permite o resgate do que pode ser significativo para uma melhor investida, tanto em nível da pesquisa que se empreende quanto da sua própria superação ao apontar para novos estudos a partir dessas percepçōes.

Compreendendo a enumeração como primeira fase deste processo de pesquisa de campo, e reconhecendo sua importância como etapa fundamental para o sucesso do momento subseqüente, entende-se que a descrição de situaçōes específicas ocorridas em cada distrito e as estratégias testadas quando da enumeração merecem uma descrição pormenorizada.

\section{Copacabana}

Considerado a área mais rica da amostra, o distrito 10 compreende todo o bairro de Copacabana e Leme, além de parte de Ipanema e de Botafogo, bairros limítrofes com características sócio-econômicas semelhantes. O tipo de habitação predominante no distrito é de prédios de apartamentos, o que dificulta a abordagem, na medida em que este tipo de moradia implica um aparato erguido em nome da segurança de seus moradores. Desde grades e portarias blindadas, passando por porteiros desconfiados e síndicos ausentes, tudo neste distrito contribui para tornar dificultosos a abordagem e o trabalho de campo.

Antes de começar o trabalho, foi feita uma primeira incursão para reconhecimento do terreno e preparação do campo para a entrada dos pesquisadores. Tomou-se um dos setores, situados no bairro do Leme, onde foi experimentado partir direto para a enumeração, batendo de porta em porta. As dificuldades foram anotadas, as características do setor descritas e, com base nessa primeira experiência, foram elaborados alguns instrumentos que seriam testados e estendidos aos demais setores para o desenvolvimento dos trabalhos.

A dificuldade maior do trabalho era o próprio acesso à população alvo da pesquisa, considerando que a situação ideal em um processo de enumeração é o confronto direto entre o pesqui- 
sador e seu futuro entrevistado. A enumeração, além de indicar um processo de localização, tem a funçāo de preparar o terreno para a entrevista. Entretanto, nem sempre essa situação ideal pode ser atingida no distrito de Copacabana. Chegar em um edifício sem contato prévio e solicitar a um porteiro que anuncie où conduza os pesquisadores aos moradores idosos gera grande desconfiança. Isto se dá mesmo quando se explica que se trata de uma pesquisa feita por uma Universidade e com todos os pesquisadores munidos de credenciais e documentos de identidade. $O$ universo sócio-cultural da maioria dos porteiros nâo facilita o entendimento desta tarefa, e a experiência que possuem desse tipo de abordagem está quase sempre ligada a vendedores, cuja entrada no prédio os porteiros têm a incumbência de impedir. No intuito de quebrar essa barreira, resolveu-se redigir uma carta ao síndico de cada prédio, na qual foi situada a temática da pesquisa, sua relevância e vinculação institucional, a qualificação e o nome do pessoal de campo envolvido, solicitando sua colaboração no sentido de divulgar a pesquisa entre os moradores e permitir a entrada dos pesquisadores no edifício. Foram feitas mais duas cartas, uma para as Associaçōes de Moradores e outra para as Delegacias de Polícia. A estratégia, com esses instrumentos, era dar cobertura institucional e abrir as portas dos edifícios aos pesquisadores.

Para a execução do trabalho, foi adotado o seguinte procedimento: agrupados os 19 setores do distrito, por contigüidade, distribuiu-se uma cota igual para cada pesquisador, que passou a ser responsável pela cobertura integral dos seus setores durante todas as etapas do processo de pesquisa. Cada pesquisador recebeu um mapa, e seguindo o percurso nele assinalado, foi possivel listar todos os edifícios de cada setor, pelo nome e endereço. Ato contínuo, entregou-se uma carta em cada edifício e, após alguns dias, voltou-se para se proceder à enumeração. Os efeitos desta estratégia variaram de setor para setor, de um prédio para outro, dependendo de inúmeras variáveis. $\mathrm{Na}$ maioria dos edifícios, os síndicos, tendo divulgado a carta para os moradores, autorizavam os porteiros a permitir a entrada de nossos pesquisadores no prédio. Em alguns casos, foi possível falar com os moradores apenas pelo interfone da portaria, 0 que se constituía um trabalho penoso, de muitas explicações repetidas e nem sempre bem compreendidas. Contudo, a desconfiança esteve sempre presente, e os números de telefone raramente foram informados. Em alguns edifícios, a dificuldade maior era encontrar o síndico presente, malgrado as inúmeras idas ao prédio. Esse movimento de idas consecutivas acabava favorecendo uma relação de maior familiaridade com os porteiros, que eram transformados em aliados, seja intercedendo favoravelmente junto ao síndico seja atuando diretamente com os moradores, facilitando, então, o trabalho. Alguns casos houve em que o porteiro, sendo antigo no prédio, era usado pelo síndico para atuar como informante ou conduzir os pesquisadores à população idosa residente. Em situaçōes raras, o síndico entregou relaçōes contendo as informaçōes buscadas. Assim como foram raros os locais onde se pôde subir diretamente até os apartamentos, também houve locais em que o trabalho não pôde ser efetivado pela omissão ou negativa total do síndico. Contudo, aparentemente ocorreram algumas irregularidades; constatouse que o trabalho de abordagem foi menos difícil na razão direta do grau de integração do síndico e do porteiro com o conjunto de moradores de seu edifício. Ao contrário, nos edifícios onde o síndico era pouco presente ou os porteiros tinham vinculação recente, o acesso foi mais difícil e a desconfiança por parte dos moradores foi mais perceptível, dificultando - e às vezes até inviabilizando o trabalho.

\section{Méier}

O distrito do Méier compreende um conjunto de bairros que se estende por uma imensa área da zona suburbana do município. Os 19 setores aleatoriamente selecionados para este distrito incluíram os bairros do Méier, Maria da Graça, Cachambi, Pilares, Del Castilho, Todos os Santos, Aboliçăo, Cavalcante, Inhauma, Engenho Novo, Engenho da Rainha, Tomás Coelho e Piedade.

O procedimento adotado para a enumeração levou em consideração as peculiaridades dessa região, uma sucessão de bairros com características urbanas comuns. $O$ tipo de habitação predominante - casas - permitiu que a abordagem 
fosse tentada sem uma ida prévia a campo, como ocorrera em Copacabana. Em vez de serem distribuídos os setores para os pesquisadores individualmente, foi experimentado o trabalho em duplas, considerando os longos deslocamentos a pé, batendo-se diretamente às portas. Com esse procedimento, visou-se principalmente à segurança pessoal dos membros da equipe, que estava recebendo um novo membro para integrá-la. A receptividade em todo o distrito do Méier foi excelente, e a enumeraçāo desta vez pôde incluir, além do nome completo e do endereço, o número do telefone (quando havia) para contatos posteriores diretos visando à marcação das entrevistas.

\section{Santa Cruz}

Localizado na Zona Oeste do município, o distrito de Santa Cruz abriga uma vasta área rural com grandes descampados, convivendo com a ocupação progressiva de um parque industrial que está mudando as feiçōes do lugar. A população concentra-se no curso do leito da estrada de ferro ou em conjuntos residenciais populares, constituindo-se em núcleos isolados, entrecortados por longos territórios com escassos moradores. Os setores sorteados cobrem uma extensa regiāo com algumas áreas caracteristicamente rurais e de baixa densidade demográfica, o que provocou longos deslocamentos dentro de um mesmo setor. Outras áreas localizam-se nas adjacências do centro polarizado em contigüidade com a linha de ocupação ao longo da via férrea; e outras, ainda, à beira-mar, confundindo-se com área de veraneio.

Essas características levaram à adoção de dois procedimentos: a açāo conjunta da equipe nos setores localizados nas áreas rurais; e o trabatho em duplas nos setores mais urbanizados. A receptividade, a exemplo do Méier, foi excelente, com a diferença de terem sidos localizados pouquíssimos aparelhos de telefone.

\section{CONCLUSÃO}

O processo de enumeração para Copacabana contou com 4 pesquisadores, para o Méier e
Santa Cruz, a participação foi de 5 pesquisadores, tendo sido consumidos 4 meses de trabalho; deste período, 2 e meio foram utilizados apenas em Copacabana. Apesar das dificuldades, principalmente neste distrito, as metas estabelecidas foram integralmente cumpridas.

As informaçōes obtidas através da enumeração foram transferidas para um banco de dados com campos para os registros dos distritos, setores, nome, sexo, idade, endereço e telefone das pessoas enumeradas. Em todos os distritos, os idosos cadastrados são em número superior à cota estipulada pelo projeto. Esta margem de sobra foi estabelecida a fim de que na seleçāo dos 260 idosos por distrito pudesse ser respeitada a proporcionalidade por sexo. $\mathrm{O}$ recurso do computador torna ainda possível a emissão de etiquetas com endereços para o envio de correspondência às pessoas selecionadas, facilitando assim o trabalho braçal desta etapa de campo.

Com todos estes estágios superados e o instrumento BOAS já testado ${ }^{14}$, o momento seguinte foi do estudo-piloto. Este visa a proporcionar uma experiência real para os trabalhadores de campo e da equipe de psiquiatras nos estudos de validação e confiabilidade do segmento de saúde mental do questionário BOAS. Também foi um objetivo testar os programas desenvolvidos para a entrada de dados e análise dos resultados dos testes. Além disto, procurou-se ganhar maior familiaridade com o programa estatístico (SAS) a ser usado nas análises das informações.

A apresentação dos resultados do piloto e do estudo de confiabilidade e validação será brevemente motivo de um novo artigo da equipe de pesquisadores do Programa da Terceira Idade do Instituto de Medicina Social da UERJ.

\section{AGRADECIMENTOS}

À Fundação IBGE/CDDI, pelo apoio prestado, e à assessoria de estatística de Ana Paula Pellegrino Bechelli e Priscila Maria Signorelli Montalvāo Montesanto. 
VERAS, R.P. et al. [A domiciliary enquiry on the elderty population in a large urban center of Rio de Janeiro, Brazil: a methodological propocal]. Rev. Satede pebL, S. Paulo, 23: 429-38, 1989.

ABSTRACT: The methodology used by a project being carried out at the Institute of Social Medicine, Rio de Janeiro, concerning the epidemiology of the elderty and the stages of the community survey are presented. The sampling methods and the steps of the enumerator process are also detailed.

KEYWORDS: Health surveys. Methods. Aged.

\section{REFERENCLAS BIBLIOGRÁFICAS}

1. ANUÁRIO ESTATISTICO DO BRASIL: 1983. (Fundaçăo IBGE). Rio de Janeiro, 1984.

2. ANZOL A-PEREZ, E. Ageing in Latin American and the Caribbean. In: Pan-American Health Organization. Toward the well-being of the elderly. Washington, D.C., 1985. p.9-24 (Scientific Publication, 492).

3. BARAT7, F. VII.I.FLA, Y. Rendimentos no Município do Rio de Janeiro. In: Instituto de Planejamento Municipal (IPI_ANRIO). 4 estudos: consolidaçöo de favelas, favelas cariocas, regularização de loteamentos, rendimentos no Rio. Rio de Janeiro, 1986. p. 53-75.

4. BARROS, M.B. de A. Consideraçôes sobre a mortalidade no Brasil em 1980. Rev. Saúde públ, S.Paulo, 18:122-37, 1984.

5. BARROS, M.B. de A. A utilizaçăo do conceito de classe social nos estudos dos perfis epidemiológicos: uma pro. posta. Rev. Sauide públ., S. Paulo, 20:269-73, 1986.

6. CARVAL.HO, J.A.M. de Estrutura de renda e padroes de fecundidade no Brasil. In: Costa, M.A., ed. Anais do Simpósio sobre o Progresso da Pesquisa Demográfica no Brasil, 1976. v.2, p.9-23.

7. GENTILE DE MELLO, C. A formaçăo do médico generalista e a medicina previdenciária. Saúde Deb., (7/8):30-8, 1978.

8. INSTITUTO DE PLANEJAMENTO MUNICIPAL (IPI ANRIO). Implantaçäo da đrea de planejarnento am biencal. Rio de Janeiro, 1985.
9. RAMOS, L.R. Health care for the elderly - an unmet need. Health and living conditions of the elderty population living in a large urban center in Săo Paulo, Brazil; project report. I ondon, Department of Community Health, London School of Hygiene and Tropical Medicine, 1985.

10. BARROS, L.R. Health care for the elderly - an unmet need. Assessing health and living conditions of an elderly living in a large utban center, Såo Paulo. London, 1986.

[PhD Thesis - London School of Hygiene and Tropical Medicine].

11. RAMOS, I.R.; VERAS, R.P.; KALACHE, A. Envelhecimento populacional: uma realidade brasileira. Rev. Saúde públ., S. Paulo, 21:211-24, 1987.

12. SANTOS, W.G. dOS; MONTEIRO, V.M.; CAILI AUX, A.M.L. Que Brasil te este? Manual de indicadores sociais; Technical Report. Rio de Janeiro, IUPERJ, 1988.

13. SILVA, N. da V. Potencial de crescimento da populaçăo brasileira. Cienc. Hoje, 1(1):58-68, 1982.

14. VERAS, R.P.; SOUZA, C.A.M.; CARDOSO, R.F.; MILIOLI, R.; DUTRA, S. Pesquisando populaçóes idosas - a impontancia do instrumento e o treinamento de equipe: uma contribuiçăo metodológica. Rev. Saúde públ, S. Paulo, 22:513-8, 1988.

15. WARNES, T. The elderly in less-developed world regions. Ageing and Soc., 6:373-80, 1986.

Recebido para publicação em 11/4/1989 Aprovado para publicaçäo em 20/6/1989 